\title{
Argumentación o retórica, una de las piezas claves para la construcción de la realidad social ${ }^{\star}$
}

\author{
Pedro Felipe Díaz Arenas" \\ Jorge Gregorio Posada Ramírez ${ }^{*}$
}

Recibido: 19 de julio de 2012 Aprobado: 8 de septiembre de 2012

\begin{abstract}
Resumen
Este artículo busca mostrar que es la retórica, y no la argumentación, la práctica humana decisiva en la construcción y sostenimiento de la realidad social. Es la capacidad de persuadir a auditorios lo que constituye los principios rectores de las instituciones sociales, y no el debate crítico y argumentado de ideas. Para esto, en la primera parte se distinguirá entre argumentación y retórica. Se mostrará que en la argumentación prima la demostración de verdades, mientras que en la retórica, el consentimiento o persuasión de auditorios. Sobre esta idea, y desde las tesis del filósofo del lenguaje John Searle acerca de la construcción de la realidad social, se mostrará que es el lenguaje persuasivo el que permite la constitución de la intencionalidad colectiva, y con ella, de los hechos institucionales, estos últimos, las unidades básicas de la realidad social. Brevemente, este artículo desarrollará el argumento: en tanto la realidad social se constituye en la intencionalidad colectiva, y la intencionalidad colectiva se forma a través del lenguaje retórico, la realidad social se constituye en el lenguaje retórico.
\end{abstract}

Palabras clave: argumentación, retórica, realidad social, verdad, validez, persuasión, adhesión.

* Este trabajo es parte de los resultados de las investigaciones adelantadas por el grupo de investigación Razones y Acciones del Programa de Filosofía de la Universidad del Quindío, desde el proyecto de investigación: Ontología de la realidad social, una perspectiva de investigación para las ciencias sociales. Sea esta la oportunidad para agradecer a la vicerrectoría de investigaciones de la Universidad del Quindío por el apoyo para la realización de este proyecto. De igual forma, es parte del trabajo interdisciplinario que el Programa de Filosofía de la Universidad del Quindío adelanta con el Programa de Comunicación social y Periodismo.

** Comunicador social, estudios de doctorado en Ciencias de la Educación Línea pensamiento y comunicación. Docente investigador, y director académico de Comunicación Social - Periodismo Universidad del Quindío. Coordinador del proyecto Internacional Imaginarios y frontera Universidad Autónoma de Ciudad Juárez, México. pfdiaz@uniquindio.edu.co

*** Licenciado y magíster en filosofía. Actualmente se desempeña como director del programa de Filosofía de la Universidad del Quindío, institución en la que además es docente investigador. Entre sus publicaciones se destaca el libro: La noción tripartita del conocimiento, y su artículo Críticas al enfoque causal de la acción propuesto por Harry Frankfurt. gposada@ uniquindio.edu.co 


\title{
Argumentation or Rhetoric, one of the Main Parts for the Construction of Social Reality
}

\begin{abstract}
The purpose of this article is to show that it is the rhetoric -but not argumentationthe human decisive practice in construction and maintenance of social reality. It is the capacity to persuade audiences what constitute the leading principles of social institutions, but not the critical argumentative debate of ideas. In the first part, there will be a distinction between argumentation and rhetoric; it will be shown that the demonstration of truths is the most important aspect in argumentation while in rhetoric, it is the acceptance of persuasion of audiences. About this idea, and based on thesis of language philosopher John Searle about the construction of social reality, it will be demonstrated that the persuasive language is the one which allows the constitution of collective intention and institutional facts, the latter as basic units of social reality. This article will briefly develop the argumentation, whilst the social reality constitutes itself in collective intentionality and this constitutes itself in the rhetorical language.
\end{abstract}

Key words: Argumentation, rhetoric, social reality, truth, validity, persuasion, adhesion. 


\section{Introducción}

Cuando Sócrates fue condenado, Apolodoro exclamó: "iSócrates, lo que me aflige más es verte morir inocente!" Sócrates, pasándole suavemente su mano por la cabeza, le dijo con la risa en los labios: "Amigo mío, ¿̇uerrías mejor verme morir culpable?"

PLATÓN

Anito, Melito y Licón, quienes acusaron a Sócrates de corruptor de jóvenes y sacrílego, persuadieron a 281 jueces de 556 sobre la culpabilidad del filósofo. Más que a razones o argumentos, estos tres sofistas apelaron a las emociones de los jueces para presentar a un Sócrates que arengaba a los jóvenes a que perturbaran las leyes de Atenas y a ser impíos con los dioses. No obstante, si Sócrates mostró que les rendía los sagrados cultos a los dioses -su vida estuvo marcada por la creencia en el Daimon - y que predicaba la sumisión a las leyes de Atenas -prefirió la muerte que las leyes atenienses la prescribían, antes que la sublevación- ¿por qué fue encontrado culpable y condenado a muerte a través de la ingesta de cicuta? El mismo Sócrates, horas antes de morir, advirtió que no siempre es la verdad la que suena agradable y persuasiva, ya que muchas veces la mentira se sirve con los mejores condimentos, haciendo de lo verdadero, insípido y reprobable, y de lo falso, agradable y creíble.

Este caso, tomado del libro Apología de Sócrates escrito por Platón (2003), permite distinguir entre la capacidad del lenguaje para describir la verdad y su igual capacidad para persuadir. El lenguaje es un instrumento que recrea los hechos, pero, a su vez, los puede configurar a los intereses del emisor. Con el lenguaje se argumenta o se persuade, pues no siempre el que argumenta persuade, o el que persuade argumenta. En tanto en la argumentación el criterio para determinar su validez o invalidez es su compromiso con la verdad, en la persuasión es la capacidad para adherir auditorios lo que define su corrección o incorrección.
Mientras que el lógico Wesley Salmon (1965) afirma que los argumentos son relaciones lógicas entre enunciados, y que es independiente e irrelevante la aceptación o no aceptación que las personas puedan tener de ellos, Chaim Perelman (2000) en el Tratado de la argumentación o nueva retórica dice que argumentar es influir por medio del lenguaje en la adhesión de un auditorio a una idea o creencia. Perelman, en su intención de alejarse de los argumentos basados en los razonamientos lógicos y en proposiciones de evidencia empírica, subtituló su tratado sobre la argumentación como la Nueva retórica. Así, la obra de Perelman, más que un estudio sobre la argumentación, es todo un tratado sobre retórica, pues como él mismo señala: "Este tratado se ocupará únicamente de los medios discursivos que sirven para obtener adhesión del auditorio, por lo que solo se examinará la técnica que emplea el lenguaje para persuadir y para convencer" (Perelman, 2000, p. 39).

Este texto asumirá la argumentación como la relación justificativa entre premisas y conclusiones, relación que se evalúa a partir de la verdad de las proposiciones y de reglas lógicas; y la retórica, en el sentido que le da Perelman, como las estrategias discursivas para adherir auditorios, para finalmente mostrar que en tanto la realidad social está constituida por estados mentales colectivos: creencias y deseos, es la capacidad de adherir a los grupos sociales a cierto tipo de creencias y deseos lo que constituye y sostiene la realidad social.

\section{La argumentación y su dependencia con la lógica y la verdad}

Pedro afirma que la ética es una disciplina que no debe ser estudiada por los comunicadores, pues los comunicadores deben ser profesionales que posean altas competencias investigativas, y en tanto la ética no propende a la formación investigativa, no debería enseñarse. Antonio sustenta lo contrario, para él debería estudiarse ética, pues los profesionales en comunicación deben tener 
un compromiso genuino con el bienestar de la sociedad, y el estudio de la ética capacita a las personas en distinguir lo bueno de lo malo, lo que es benéfico de lo que es perjudicial, conocimiento necesario para aquel que tenga el compromiso de jalonar el bienestar de las personas. Tanto Pedro como Antonio justifican una idea, defienden una de sus creencias. Pedro defiende la tesis de que no debería enseñarse ética en la carrera; Antonio, que debería enseñarse. A pesar de que son tesis contrarias, ambos tienen razones para creer lo que afirman, argumentan a favor de una idea. Esquemáticamente Pedro argumenta:

P1 Los comunicadores deben poseer altas competencias investigativas

P2 La ética no propende a la formación investigativa

\% La ética no debe enseñarse en Comunicación

Y Antonio:

P1 Un profesional en comunicación debe propender por el beneficio de la sociedad

P2 Para propender por el bienestar de la sociedad se debe saber qué es lo benéfico y perjudicial para ella

P3 La ética enseña qué es lo bueno y benéfico, y lo malo y perjudicial para las personas, y con ellas, la sociedad

\% La ética debe enseñarse en la carrera de Comunicación

Donde P representa las premisas del argumento y el símbolo \% la conclusión. Esto porque un argumento es un conjunto de proposiciones ordenadas de tal forma que unas sirven para respaldar o justificar a otras. A las proposiciones que respaldan se les reconoce como premisas, y a la proposición respaldada como conclusión. Así, las premisas son la información, descrita en enunciados, de las que se vale el emisor para probar la verdad de la afirmación que presenta o quiere defender. La conclusión es la información, también presentada en enunciados, que infiere o deriva el emisor de las premisas. Es de subrayar que tanto las premisas como la conclusión de un argumento siempre son dadas en el uso informativo del lenguaje. En esto se distingue el argumento del razonamiento, pues si bien razonar es inferir o derivar de unos datos otros datos, cuando se razona no es necesario hacer uso del lenguaje. En tanto los razonamientos se presenten en el lenguaje, se revistan de palabras, convirtiendo tantos los datos de que se parte para razonar, como el resultado del razonamiento, en enunciados, se tiene no un simple razonamiento sino un argumento. Así, todo argumento es un razonamiento, pero no todo razonamiento es un argumento. José Díez en su libro Iniciación a la lógica resume lo anterior cuando dice: "Y los argumentos no son afirmaciones, son series de afirmaciones con cierta característica, a saber, que de esa serie de afirmaciones se pretende que una de ellas se siga de las restantes" (Díez, 2002, p. 15).

Así, las premisas de Pedro son: (P1) "Los comunicadores deben poseer altas competencias investigativas y (P2) "La ética no propende a la formación investigativa" y su conclusión: (\%) "La ética no debe enseñarse en Comunicación". En el caso del argumento de Antonio este se basa en tres premisas: (P1) "Un profesional en comunicación debe propender por el beneficio de la sociedad", (P2) "Para propender por el bienestar de la sociedad se debe saber que es lo benéfico y qué es lo perjudicial para ella" y (P3) "La ética enseña qué es lo bueno y benéfico, y lo malo y perjudicial para las personas, y con ellas, la sociedad". De estas, Antonio infiere o deriva que: (\%) "La ética debe enseñarse en la carrera de Comunicación". 
Aristóteles, reconocido entre otras formas como el maestro de la lógica, se refiere a los silogismos, una de las formas prototípicas de la argumentación, como el tipo de estructura en la que:

(...) una vez sentadas ciertas proposiciones, se concluye necesariamente en otra proposición diferente, solo por el hecho de haber sido aquellas sentadas. Cuando digo solo por el hecho de haber sido sentadas las primeras proposiciones, quiero decir que a causa de ellas resulta probada la otra proposición (Analíticos Primeros I, 1, 24 b 20-25).

Los argumentos adecuadamente formados son aquellos en los que las premisas respaldan plenamente a la conclusión, clasificándose como válidos o inválidos. Los primeros son aquellos en los que la conclusión se deriva o se infiere adecuadamente de las premisas; los argumentos inválidos son aquellos en los que la conclusión no se deriva adecuadamente de las premisas. La validez es una propiedad formal de los argumentos, tiene que ver solo con la estructura relacional entre premisas y conclusiones. Con independencia de que las premisas sean verdaderas o falsas, si de ellas puede derivarse la conclusión se clasificará el argumento como válido. Por esto, muchos argumentos a pesar de que tengan premisas falsas, son válidos en tanto la conclusión se infiriere de estas. El siguiente es un caso de argumento válido, aunque tiene premisas falsas:

P1 Todo el que nace en Medellín y come arepas es filósofo

P2 Sócrates nació en Medellín y comió arepas

\% Sócrates fue filósofo

Al leer desprevenidamente las premisas, la conclusión surge espontáneamente. Esto porque la conclusión realmente se deriva de las premisas.
En símbolos, la forma de este argumento es: P1: todos los $\mathrm{N}$ que tienen la propiedad C, son F. P2: $\mathrm{S}$ es $\mathrm{N}$ y tiene la propiedad $\mathrm{C}$, de lo que se sigue que \% $\mathrm{S}$ es $\mathrm{F}$.

Por disparatado que sea el anterior argumento, cumple con uno de los criterios de corrección de la argumentación: que de las premisas se pueda derivar la conclusión. No obstante, como puede intuirse, este criterio es necesario pero no suficiente para la adecuada argumentación. La corrección formal, como criterio lógico, permite establecer estructuras correctas de argumentación, las que sumadas a unos apropiados y honestos usos de la verdad, llevan a la construcción final de buenos argumentos, de argumentos sólidos. A la validez de los argumentos hay que adicionar la condición de que las premisas sean verdaderas; con esto no tendremos simplemente argumentos válidos, o argumentos que tienen premisas verdaderas, sino argumentos sólidos.

Es canónico en los textos de argumentación que una característica de los argumentos es su estructura formal, la que se evalúa como válida o inválida, y otra es su condición veritativa, es decir, su conexión con la verdad. En este caso, no son propiamente los argumentos los que se evalúan como verdaderos o falsos, sino las proposiciones que los conforman. Son las premisas y la conclusión individualmente las que se evalúan como verdaderas o como falsas. El filósofo del lenguaje Ludwig Wittgenstein en su libro Tractatus Logico Philosophicus (1994) expuso con excesivo rigor lógico que la verdad es una propiedad exclusiva de las proposiciones, de los enunciados que describen el mundo. Si en el enunciado se proyecta el modo de ser de algún suceso del mundo, el enunciado es verdadero, en caso contrario será falso. La verdad y la falsedad se establecen a partir de la adecuación o no adecuación de las proposiciones con los hechos del mundo. Así, si bien el argumento: Todo el que nace en Medellín y come arepas es filósofo, como Sócrates nació en Medellín y comió arepas, por lo tanto, Sócrates fue filósofo, 
es válido, en tanto sus dos premisas son falsas, pues no se adecuan a los hechos del mundo, es un argumento que no cumple con los criterios de corrección que exige toda buena argumentación.

Consistencia o solidez son los predicados que definen las condiciones óptimas de los argumentos, pues los argumentos consistentes o sólidos son aquellos que son válidos, y que, además, contienen premisas verdaderas. La consistencia implica que tanto la estructura formal del argumento, como su condición veritativa son las correctas. Así, la validez, o su estructura lógica, y el valor de verdad de las premisas son las características que definen y constituyen los argumentos que pasan la revisión crítica, la que, en su compromiso con lo coherente y veraz debe desatender y no tomar como justificadas las tesis o afirmaciones que se presenten en razones que no son válidas ni veraces. Como puede verse, la validez y el valor de verdad son criterios impersonales. El que una conclusión se siga de unas premisas es un proceso enmarcado en las reglas universales y necesarias del pensamiento lógico. Las voluntades, los contextos humanos son irrelevantes a las reglas de inferencia que permiten la validez de los argumentos. Si todo A está en B, y todo C está en A, se sigue necesaria y universalmente que todo $C$ esta en B. Lo mismo puede decirse de la noción de verdad. A pesar de los fuertes ataques a lo que sea este criterio de corrección de los argumentos, la afirmación: "Todo el que nace en Medellín y come arepas es filosofo" es falsa; el enunciado "El filósofo que fue maestro de Platón no es de Medellín" es verdadero, y tanto la falsedad del primer enunciado como la verdad del primero es independiente de las personas que las emitan y de los auditorios que las escuchen.

\section{La retórica y su dependencia a los oradores y auditorios}

Pedro inicia el discurso ante el comité de investigaciones de su universidad señalando la importancia que para él y sus compañeros de es- tudio ha representado su formación investigativa. Afirma que gracias a los cursos que los miembros del comité de investigaciones han impartido su habilidad para hacerse preguntas pertinentes, formular hipótesis y lanzar conjeturas explicativas ha incrementado notablemente. Por lo que cree que como estudiante sería más apropiado dedicar más tiempo en su formación investigativa para seguir progresando en los objetivos que el comité de investigaciones ha propuesto, objetivos que no están presentes en los cursos de Ética. Concluye que cursos como los de Ética o Humanidades deberían cederle créditos y tiempo al área de Investigación, pues con esto se propendería a formar comunicadores con alta vocación y competencia investigativa.

Perelman en el Tratado de la argumentación, nueva retórica afirma que la argumentación no tiene más propósito que persuadir o convencer a auditorios. Por esto, propone que su estudio no se haga a la manera clásica: a partir de la conexión lógica entre premisas y conclusiones: validez, ni en la relación de las proposiciones con los hechos: verdad. Para Perelman en tanto el propósito de un orador es adherir a los oyentes a sus intereses y creencias, los argumentos deben analizarse en función del orador, del auditorio, y de las creencias que unos y otros trenzan en la relación comunicativa. Así, conceptos como verdad, validez e inferencia lógica son en Perelman canjeados por los de auditorio, orador, creencias, adhesión, persuasión y convicción.

A la manera de libros clásicos como el Arte de la retórica de Aristóteles el estudio de Perelman llaman la atención en las condiciones sociologías, antropológicas y psicológicas de los humanos que participan en el acto comunicativo de la argumentación, y no en los argumentos mismos. Así, el análisis retórico se centra en los sujetos, y podría decirse que pone en un segundo plano a los argumentos, entendidos como sucesión de afirmaciones en las que unas apoyan o permiten derivar otras. Aristóteles al referirse a los argumentos retóricos afirma: "Pues el discurso está 
compuesto de tres cosas: el que perora, aquello de que habla, y aquel a quien habla, y el fin del discurso se refiere a este, es decir, al oyente." (Aristóteles, 2002, p. 91).

Mientras que en la argumentación las premisas se conectan con los hechos, conexión que permite sus evaluaciones como verdaderas o falsas, en la retórica las premisas se conectan con las creencias adoptadas por el auditorio al que se dirige el orador. Perelman es enfático en que en tanto los argumentos retóricos no tienen otra finalidad más que la adhesión, el punto de partida no son llanamente las proposiciones llamadas premisas, sino las proposiciones que como premisas han de ser compartidas y aceptadas por el auditorio. Perelman dice:

Dicha conformidad versa ora sobre el contenido de premisas explícitas, ora sobre los enlaces particulares utilizados, ora sobre la forma de servirse de ellos: de un extremo al otro, el análisis de la argumentación atañe a lo que se supone admitido por los oyentes. (Perelman, 2000, p. 119)

Las premisas de un argumento retórico no se evalúan en relación con los hechos del mundo, por lo que su valor veritativo es irrelevante. Las adecuadas premisas retóricas son aquellas que entre en comunión con las creencias y deseos del auditorio, independientemente de que estas creencias sean verdaderas o justificadas, o de que los deseos sean los apropiados. Por esto, al orador retórico no le interesa la verdad ni la falsedad, sino que desde el comienzo de su exposición se cuenta con el consentimiento del auditorio. Esto puede verse recreado en el argumento inicial de esta sección. Pedro afirma que:

P1 La investigación es de suma importancia para la formación profesional

P2 Los cursos de investigación impartidos por los miembros del comité de investigaciones son de elevado nivel formativo
P3 Son los cursos de investigación y no los de ética los que permiten alcanzar adecuadas competencias académicas.

\% Deben cambiarse los cursos de ética por cursos de investigación

Las tres premisas de este argumento, dirigido a un auditorio conformado por un comité de investigaciones, son premisas fácilmente asentidas. El orador ha logrado que las afirmaciones iniciales de su exposición comulguen con las creencias y deseos del auditorio. Ya sea por casualidad o por una estrategia del orador, el acuerdo inicial entre este y su auditorio, acuerdo dado en el contenido de las premisas que el orador expone, y las creencias propias del auditorio, empieza a sugerir un adecuado uso de las condiciones retóricas para lograr adhesión.

Aristóteles, en el Arte retórica, exhorta a que los oradores conozcan previamente a las personas a las que dirigirán sus discursos. El buen retórico conoce las disposiciones sociologías y psicológicas de sus auditorios, pues es en este conocimiento en el que debe basar la obtención de los acuerdos iniciales. Por ejemplo, para Aristóteles si un orador quiere persuadir a un grupo de jóvenes sobre una idea, él debería saber con respecto a los jóvenes que:

Y no son mal intencionados sino ingenuos, porque todavía no han sido testigos de muchas maldades. Y son crédulos, porque todavía no han sido engañados en muchas cosas. Y están llenos de esperanzas; porque de manera semejante a los alcohólicos, los jóvenes son calientes por naturaleza y, al mismo tiempo, porque aún no han sufrido desengaño en muchas cosas. Y así viven la mayoría de las cosas con la esperanza, porque la esperanza mira a lo que es futuro, mientras que el recuerdo mira al pasado, y para los jóvenes lo futuro 
es mucho y lo pretérito breve; ya que el primer día de nada pueden acordarse y en cambio pueden esperarlo todo. Y son fáciles de engañar, por lo dicho, porque esperan fácilmente (Aristóteles, 2002, p. 163).

Retomando el argumento de Pedro, al parecer este asume como premisas lo que conoce de su auditorio, y su intención no es justificar, explicar o demostrar la verdad de la conclusión: \% "Deben cambiarse los cursos de ética por cursos de argumentación"; su propósito es que dadas las premisas, en retórica, los acuerdos iniciales, estos arrastren a la adhesión de la afirmación final. En los argumentos retóricos la conclusión no es lo que se infiere de las premisas, sino la afirmación o creencia que el orador busca fijar en la mente de sus oyentes. Creencia que puede ser fácilmente arrastrada cuando se conecta, no lógica, sino psicológicamente, con las ideas inicialmente convenidas.

Así, mientras en los argumentos como tales la conexión entre premisas y conclusiones es lógica, en el caso de los argumentos retóricos es psicológica. Las premisas no fungen como evidencias de la conclusión, sino como herramienta sugestiva que evoca afectos y sentimientos, estados mentales que relajan la mente para la aceptación de cualquier conclusión. A la natural dificultad de argumentar con validez, se suma en el argumento retórico la instigación a la naturaleza emotiva y sensitiva del hombre, la que tiende a debilitar y distraer sus capacidades críticas y lógicas, dejándolas a la merced de las intenciones del orador: que se adhieran a la conclusión de su argumento retórico, conclusión, y se acentúa, no es aquello justificado o sustentado en premisas, sino que es los intereses o creencias exitosamente subastadas de un orador. De los tres libros que componen el Arte retórica de Aristóteles, el segundo libro y más extenso es todo un tratado sobre las pasiones humanas. Para el filósofo griego el orador retórico debe tener un conocimiento superlativo de pasiones, porque sobre estas, debe preparar a su auditorio. El argumento retórico exitoso es el que ha contemplado en la construcción de sus premisas la disposición del ánimo del auditorio.

Los hechos, que dentro de la argumentación no retórica se entienden como los sucesos que acaecen en el mundo con independencia del sujeto, siendo además las instancias evaluativas de las proposiciones, de tal manera que si encajan con ellas las hacen verdaderas, y en caso contrario falsas, en la argumentación retórica se entienden como una construcción social. Perelman al definir lo hechos dentro del contexto de la argumentación retórica señala que:

Todo lo contrario, debemos insistir en que, en la argumentación, la noción de "hecho" se caracteriza únicamente por la idea que posee cierto genero de acuerdos respecto a ciertos datos, los que aluden a una realidad objetiva y que, según $H$. Poincaré, designaría, en realidad: "lo que es común a varios seres pensantes y podría ser común a todos" (Perelman, 2000, p. 121)

Inmersos en una ola de literatura sociológica y filosófica que va desde autores como Emile Durkheim (1999) hasta pensadores como Karl Popper (1994) y Thomas Kuhn (1998), el punto de vista la argumentación retórica es que los hechos no son entidades espaciales y temporales que existen fuera de los sujetos. Los hechos son acuerdos macizos logrados en la intersubjetividad. Los hechos que se perciben dependen de las creencias y predisposiciones de los observadores, señala Karl Popper en su libro Conjeturas y refutaciones (1994). Thomas Kuhn cuando se refiere a las comunidades científicas, las que se asumen como modelos de objetividad, no escatima en señalar que en tanto cambian los marcos conceptuales y las creencias de los científicos, cambia el mundo mismo que perciben. Dice:

Es algo así como si la comunidad fuera transportada repentinamente a otro planeta, donde los objetos familiares se 
ven bajo una luz diferente $y$, además, se les unen otros objetos desconocidos. Por supuesto, no sucede nada de eso: no hay transplantación geográfica; fuera del laboratorio, la vida cotidiana continúa como antes. Sin embargo, los cambios de paradigma hacen que los científicos vean el mundo de investigación, que les es propio, de manera diferente. En la medida en que su único acceso para ese mundo se lleva a cabo a través de lo que ven y hacen, podemos desear decir que, después de una revolución, los científicos responden a un mundo diferente. (Kuhn, 1998: 176)

De esto se puede colegir que en tanto las creencias sobre cómo son los hechos dependen de las distintas formas de percepciones de los agentes, formas que además se subordinan a los presupuestos y marcos conceptuales de los perceptores, cambiar o negociar, con los presupuestos y marcos conceptuales de los agentes, es cambiar o negociar con las creencias que las personas tienen sobre los hechos que observan. Para la argumentación retórica no existen sucesos o acontecimiento contundentes que sirvan como patrones de decisión sobre lo verdadero o falso, todo hecho es replicable y movible. La relación discursiva retórica entre orador y auditorio permite la mutación misma de los acontecimientos, pues el éxito de un argumento retórico, la adhesión de un auditorio a las creencias de un orador, excluye la validez y la verdad como criterios de corrección.

En resumen, mientras que en los argumentos retóricos las premisas propenden por adecuarse con las creencias del auditorio, en los argumentos no retóricos estas buscan la correspondencia con los hechos. En tanto un argumento no retórico es consistente y sólido cuando su conclusión deriva de premisas verdaderas, el éxito de los argumentos retóricos está en que la conclusión logre ser fijada y creída en la mente del auditorio.

En lo que sigue este texto describirá la constitución de la realidad social, a partir de la obra del filósofo del lenguaje John Searle. No será una descripción exhaustiva, sino que propenderá por realzar el papel del lenguaje en su constitución. Una vez esto, se mostrará que es la argumentación retórica la que permite la constitución y sostenimiento de los hechos sociales, y no la argumentación válida y veritativa.

\section{La dependencia ontológica de la realidad social al lenguaje}

La gran masa de helio que da calor y vida al planeta Tierra es un hecho tan real como el conflicto armado en Colombia. Los conflictos armados son hechos tan genuinos, que tienen, como el Sol, poderes causales sobre lo que existe. No obstante, el Sol y las guerras tienen un modo de ser distinto. Mientras que el primero existe con independencia de los humanos, los segundos solo existen si existen los humanos. Hay una distinción ontológica, esto es, una diferencia en los modos y condiciones de existencia de uno y otros. El Sol existe, tiene unas condiciones ontológicas de ser, que son independientes e indiferentes a los acuerdos humanos. Las guerras o los conflictos humanos dependen para su existencia de los humanos y sus acuerdos.

El filósofo del lenguaje John Searle en su texto ya clásico de la filosofía del lenguaje y de la sociedad: La construcción de la realidad social, clasifica la ontología del mundo en dos tipos de hechos: hechos brutos y hechos institucionales. Dice:

Hace años bautice a algunos de los hechos que dependen del acuerdo humano como "hechos institucionales" para distinguirlos de los hechos no institucionales o "brutos". Llamo a los hechos institucionales así porque, para su existencia, requieren de instituciones humanas. Para que este pedazo de papel sea un billete de cinco dólares, por ejemplo, tiene que haber la institución humana del dinero. Los hechos brutos no requieren, para su existencia, instituciones humanas (Searle, 1997, p. 21). 
Así, el matrimonio, la propiedad privada, los Estados, las universidades con sus profesores y estudiantes, los gobiernos, todo tipo de relaciones civiles, y un largo etc., en el que se contiene toda la realidad social, solo son posibles gracias a los acuerdos humanos. En el mismo tenor de Durkheim (1999), para John Searle existen porciones de la realidad que son tan objetivas y rocosas como la Luna y los planetas, pero que existen gracias a los acuerdos y convenciones humanas, de tal suerte que si desaparecen los humanos, desaparecen este tipo de hechos: los hechos institucionales.

Dos son las características esenciales que permiten la creación y el sostenimiento de estos hechos: el lenguaje y la intencionalidad colectiva. Si bien, en el aparato conceptual con el que el filósofo de Berkeley explica los hechos institucionales resalta otro tipo de categorías, para los propósitos de este artículo, son el lenguaje y la intencionalidad colectiva, los puntos decisivos para ilustrar la constitución de la realidad social.

El valor social que en Colombia se le da a ese pedazo de papel que posee dibujado el rostro de Jorge Isaacs, y una serie de imágenes alusivas a su novela María, pedazo de papel que además es expedido por la imprenta de billetes del Banco de la Republica de Colombia, no está en lo que como objeto físico ese pedazo de papel es, sino en lo que representa para los que lo poseen. Un billete de cinco mil pesos no es en esencia papel, sino la serie de creencias y representaciones que las personas tienen de él. Otro tanto puede decirse de los matrimonios, de la propiedad privada, de los gobiernos, de los Estados, de las universidades; estos hechos, si bien se instauran en elementos físicos, su naturaleza esencial desborda lo material para pasar a ser lo que los humanos se representan de ellos.

El carácter representativo de los hechos institucionales lo explica Searle a partir de la capacidad humana de tener estados mentales intencionales.
Searle define los estados mentales intencionales como: "Aquella propiedad de muchos estados y eventos mentales en virtud de la cual estos se dirigen a, o son sobre o de, objetos y estados de cosas del mundo" (Searle, 1992, p.17). Por ejemplo, la creencia de que "El 31 de octubre va a llover en la noche" es un estado intencional, porque esta creencia se refiere o representa un hecho del mundo. Todas las creencias y deseos de las personas tienen la propiedad de ser intencionales, pues estos estados mentales siempre se refieren o tratan sobre algo. No existen creencias a secas o deseos solo, siempre una creencia o un deseo se refiere a algo. Siempre se cree que, o se desea que, pero no se cree o se desea llanamente. Se cree que algo es del caso, o se desea que acontezca algo. Así, puede entenderse la intencionalidad como la capacidad humana de representar mentalmente los hechos del mundo a través de estados mentales. Representar un pedazo de papel como un objeto que vale o cuenta como medio de intercambio de bienes y servicios es otro caso típico de intencionalidad.

Es entonces en las creencias colectivas de que un pedazo de papel debe verse y representarse como un billete de 50 mil pesos, en las que el papel deja de ser simple papel para convertirse en dinero. Los acuerdos humanos, establecidos por la capacidad de las personas de tener creencias con contenidos intencionales colectivos, intencionalidad colectiva, son entonces los que permiten no solo la representación de los hechos institucionales, como el dinero, por ejemplo, sino su creación y sostenimiento. En este punto, es pertinente describir lo que se entiende por intencionalidad colectiva. La capacidad de representación y con ella de que algunos estados mentales se refieran a hechos del mundo, no es un asunto privado y singular. La convivencia social evidencia la capacidad de las personas de representar y de tener creencias colectivas. Las personas pueden creer las mismas cosas acerca de la utilidad y función de un billete de 50 mil pesos. Al compartir creencias y representaciones comunes las perso- 
nas poseen intencionalidad colectiva. Al respecto Searle dice:

Muchas especies animales, la nuestra señaladamente, poseen una capacidad para la intencionalidad colectiva. Lo que quiero decir con esto es que no sólo se comprometen en una conducta cooperativa, sino que comparten también estados tales como creencias, deseos e intenciones. (Searle, 1997, p. 41)

Es aquí cuando el lenguaje se inserta como un componente esencial para la constitución de la realidad social. Pues solo es posible establecer acuerdos colectivos, tener las mismas creencias acerca de ciertos hechos del mundo, cuando a través del lenguaje los agentes traducen públicamente lo que creen y representan. Sin un medio externo y de comprensión colectiva que permita abrir públicamente lo que creen las personas, los acuerdos sobre cómo interactuar, por ejemplo, con el dinero, no serían posibles los hechos institucionales.

El filósofo de la mente Tim Crane en su libro La mente mecánica recrea un caso que ilustra el anterior punto. (2008). En 1972, cuando la Nasa envío el Pionner 10 al espacio, aprovechó para dibujar en sus partes exteriores una serie de figuras, entre otras, la silueta de un hombre y una mujer alzando los brazos en señal de saludo. La intención era que si alguna forma de vida alienígena viera la nave entendieran el interés humano de un contacto pacífico con otras maneras de vida. Como lo señala Crane, este ensayo de establecer un contacto con extraterrestres es prácticamente fallido, pues supone hechos improbables: la existencia de otras formas de vida inteligente, con capacidades sensoriales similares a las nuestras, y más improbable aún, dotadas de un lenguaje de estructura similar a la humana. La comprensión de los símbolos del lenguaje humano, se debe a una condición intrínseca de su naturaleza, condición por la cual las personas logran identificarse como especie y asociarse para la vida social. El lenguaje le permite al emisor exteriorizar sus pensamientos, y al auditor, interiorizar los del emisor, y es, además, la manera como la intencionalidad colectiva se hace pública y simbólica en los objetos físicos que portan los hechos institucionales. En lo anterior radica la primera forma de participación del lenguaje en la constitución de los hechos institucionales. A través de él, la intencionalidad colectiva se hace pública, intencionalidad colectiva que es la base para la obtención de los acuerdos.

El segundo aspecto, muy relacionado con el anterior, y en el que la retórica muestra su valor, es la necesidad de establecer creencias comunes en los individuos, creencias que una vez aceptadas por un grupo social se instauren como creencias colectivas. La intencionalidad colectiva es la que permite ver un pedazo de papel como un objeto de valor, un trozo de madera como una entidad sagrada, una línea de pintura marcada en un espacio como una frontera. Los hechos institucionales se crean cuando a través de la capacidad persuasiva de un individuo o un grupo de ellos, un objeto deja de verse como una entidad física y se empieza a recrear mentalmente como dotado de otro valor. Así, y como se anotó anteriormente, si bien la argumentación no retórica busca que las premisas describan cómo son los hechos, la argumentación retórica señala cómo deberían verse los hechos, cómo colectivamente debería creerse en ellos y aceptarse. La argumentación dice cómo son las cosas, la argumentación retórica cómo deben verse las cosas. Los hechos institucionales más que cosas físicas y temporales del mundo son formas de pensar, de observar e interactuar colectivamente con entidades del mundo, entidades que son en tanto se cree y se piense que son lo que son. El dinero no es papel, sino los pensamientos, creencias y formas de interacción humana que se tienen de ese papel. En este sentido el lenguaje de la realidad social, debe ser aquel en el que se privilegien las creencias, intereses y deseos de los individuos, pues son ellos, los que constituyen la esencia de estos hechos; justamente, este es el lenguaje retórico. Así, un orador que desprestigie 
el valor del dinero, que pueda hacerle creer a su auditorio que no es más que papel o un vil objeto social, logrará que desaparezca el hecho en cuestión. Si alguien persuade a las personas de que dejen de ver el dinero como dinero, al crucifijo como crucifijo, o al profesor como profesor desaparecerán los hechos institucionales dinero, crucifijo y profesor, y seguramente solo quedarán el papel, el trozo de madera y el hombre. Y las fibras de celulosa que conforman el papel, la parte del árbol del que se extrajo la madera, y la materia corporal de hombre -hechos brutos - no dejarán de ser lo que son, a pesar de la elocuencia de un buen orador retórico.

El papel del lenguaje retórico es tan indispensable para los hechos institucionales, que su uso excesivo acompañado de otras manifestaciones simbólicas sostienen su estructura, Searle dice:

Los ejércitos, los juzgados y, en menor medida, las universidades se sirven de ceremonias, insignias, togas, honores, rangos, y hasta música, a modo de estímulo de aceptación continuada de la estructura. Las cárceles necesitan menos de esos mecanismos porque disponen de la fuerza bruta. (Searle, 1997, p.129)

Así, en tanto un hecho institucional es un objeto físico representado y creído, gracias a la intencionalidad colectiva como un individuo o grupo de personas quiere que se crea y represente, es el lenguaje retórico el que permite su constitución. De otra parte, en tanto el sostenimiento del hecho institucional depende de que se mantengan las creencias colectivas, la intencionalidad colectiva sobre ese hecho, es el lenguaje retórico el que, al fijar creencias, permite que se conserven.

\section{Conclusiones}

Al definir las formas de argumentación no retóricas, se mostró que estas dependen para su adecuada constitución de dos criterios: verdad y validez. Así, un argumento es sólido si su con- clusión se sigue de sus premisas y, además, estas son verdaderas. En el caso de los argumentos retóricos, ni la validez ni la verdad son adecuados criterios de corrección, pues en tanto el objetivo de la retórica es la adhesión de un auditorio a las creencias de un orador o emisor, más que conexiones lógicas o válidas, la exitosa retórica establece relaciones psicológicas entre premisas y conclusión. De igual forma, los argumentos retóricos no tienen como meta la verdad de las premisas, sino su aceptación por parte de un auditorio, con independencia de que sean falsas o verdaderas. Así, mientras el argumento no retórico busca explicar o justificar la ocurrencia de ciertos hechos, los argumentos retóricos buscan fijar y adherir creencias en los auditorios.

Una vez descrito esto, se pasó a mostrar que los hechos institucionales son entidades físicas que a través de la intencionalidad colectiva, son representados y creídos como objetos que comportan una estructura que va más allá de meros rasgos materiales. Los hechos institucionales dependen de las creencias colectivas, mientras que los hechos brutos existen con independencia de ellas. El papel existe haya o no haya humanos con sus creencias e intencionalidad colectiva; el dinero solo existe, en tanto las personas perciban y crean que ese objeto porta un valor que excede sus propiedades físicas; sin personas con ese tipo de creencias y representaciones, el dinero deja de ser dinero y pasa a ser simplemente papel.

De estas dos ideas, este trabajo intentó mostrar que siendo la retórica el uso del lenguaje que busca fijar creencias y representaciones en los grupos sociales, y que los hechos institucionales solo son, en tanto las personas alberguen colectivamente creencias y representaciones comunes, son los argumentos retóricos los más idóneos para la creación y conservación de la realidad social. En tanto los argumentos describen y explican los sucesos del mundo, y los argumentos retóricos, cómo debe verse y creerse sobre el mundo, es la retórica la que determina la realidad social. 


\section{Bibliografía}

Aristóteles. AÑO Analíticos primeros. Barcelona: Gredos (2002). Arte retórica. México: Porrúa

Crane, T. (2008). La mente mecánica, introducción filosófica a mentes, máquinas y representaciones mentales. México: Fondo de Cultura Económica.

Durkheim, E. (1999). Las reglas del método sociológico. Navarra: Folio.

Kuhn, T. (1998). La estructura de las revoluciones científicas. Santa Fe de Bogotá: Fondo de cultura económica

Perelman. C. (2000). Tratado de la argumentación, la nueva retórica. Madrid: Gredos.
Platón. (2003). Diálogos. México: Porrúa

Popper, K. (1994). Conjeturas y refutaciones, el desarrollo del conocimiento científico. Barcelona: Paidos.

Salmon, W. (1965). Lógica. México: UTEHA.

Searle, J. (1997). La construcción de la realidad social. Barcelona: Paidós.

(1992). Intencionalidad, un ensayo en la filosofía de la mente. Madrid: Tecnos

Wittgenstein, L. (1994) Tractatus lógico philosophicus. Barcelona: Altaya.

Diez, J. (2002). Iniciación a la lógica. Barcelona: Ariel. 
